\title{
The Role of Sustainable New Product Development in Demand Driven Chains
}

\author{
Elmira Naghi Ganji \\ Applied Engineering and Management \\ Faculty of Engineering \& Science, University of Greenwich \\ Chatham, United Kingdom \\ e.naghiganji@gre.ac.uk
}

\author{
Alec Coutroubis \\ Applied Engineering and Management \\ Faculty of Engineering \& Science, University of Greenwich \\ Chatham, United Kingdom \\ a.d.coutroubis@gre.ac.uk
}

\author{
Satya Shah \\ Applied Engineering and Management \\ Faculty of Engineering \& Science, University of Greenwich \\ Chatham, United Kingdom \\ s.shah@gre.ac.uk
}

\begin{abstract}
In current global and competitive environments, innovation is considered as a key success factor towards growth and meeting customer demands and expectations within the product development processes. The research paper aims to explore the concept of sustainable new product development practices within demand-driven supply chain environments. It will investigate the early stages of the research study within this domain through the findings from literature focusing on demand chain and new product development and the use of sustainable practices within manufacturing. The researcher's focus is to further develop the understanding to propose a novel framework of NPD (New Product Development) to DCM (Demand Chain Management) to utilize the research findings. The study has identified the incorporation of NPD-DCM considering all the business ecosystem entities and the flow of information, finances and materials within the supply chain structure. The results of this study can be utilized by researchers and practitioners researching within similar context and environments.
\end{abstract}

Keywords-sustainable development; new product development (NPD); supply chain; demand chain management; environmental practices.

\section{INTRODUCTION}

Traditionally, Supply Chain Management (SCM) has been considered mainly as an approach towards satisfying the needs and wants of products and services by the customers, and companies would integrate their business activities across their entire value chain networks. However, recent years have seen a tremendous growth of the concept of Demand Chain Management (DCM) similar to that of SCM through the focus on various aspects of the business, including marketing, product development, and wider aspects of strategic development of the firm's products and services. It has also been argued through earlier research in this area that considers DCM as broad scope compared to SCM as it also focuses on developing the understanding of the customer demands, as well as improving the organisational ability within the product and service optimisation to satisfy and fulfil the needs of the market and the customer expectations [1].
The research focus of this paper is towards developing an early stage understanding on the concept of demand chain management and its contribution and linkages to sustainable new product development process through the supply chain concept. Today's business and customer focused environments are rapidly changing due to the need of managing and addressing the customer's preferences and expectations within the market space. Some of the factors driving this change are the increased pace of new technological advancements such as that of Big Data and Internet of Things (IoT), shorter product lifecycles and increasing higher product offerings, variety and shorter lead times for the product to market. This impacts the overall organisational performance of the business due to increasing uncertainty due to the factors as highlighted earlier [2]. Today's competition is not only focussing on different firms, however between different supply chains and hence, competitive advantage has also transferred from single dimension to more multiple supply chain entities [3].

\section{LITERATURE REVIEW}

This literature review aims to develop a better understanding of the concepts that seem to play a vital role towards the adoption of sustainable practices in new product development environments within demand chain management. This study will provide a framework that serves for the future research and analysis of application and use of sustainable and environmental practices within demand-chain environments of manufacturing industries.

\section{A. Demand Chain Management}

The first early research on demand chain management started when researchers suggested that the first step towards developing a supply chain strategy is to consider the nature of the demand for a firm's products, and that these products were either functional or innovative in nature. It was identified that functional products were ideally fast moving consumer goods and were readily available in the market space, which had the potential towards satisfying customer needs and requirements, 
and were not subject to major changes over a period of time [4]. Research studies also focused towards designing a supply chain network that was able to link and fulfil the demand patterns linked to the overall function of the supply chain. In the earliest model developed, all of the functional products required an efficient SC network where the total cost of production, transportation, and inventories are minimised [4]. Studies highlight that demand chain management mainly focuses towards the importance of efficiency and production, similar to that of SCM and that it should be linked appropriately with the relative aspects of supply chain activities to achieve higher competitive advantage with customer satisfaction [3]. It has also shown through research that the competitive situation has advanced the pace of innovation through its discovery, implementation, introduction and diffusion into the market space. This has forced many companies to use continuous innovation within their products and services to provide and satisfy better performance from the consumers [5]. It has been noticed in recent years, that the power focus has been shifted from producers, manufacturers and retailers more towards buyers and end users [6].

TABLE I. Roles OF MARKETING PRACTICES IN DCM [7].

\begin{tabular}{|c|c|}
\hline $\begin{array}{c}\text { Demand Chain } \\
\text { Management Element }\end{array}$ & Relevance in Marketing \\
\hline $\begin{array}{l}\text { Process - } \\
\text { Managing the integration } \\
\text { between the demand and } \\
\text { supply processes }\end{array}$ & $\begin{array}{l}\text { - Facilitating the process integration } \\
\text { by disseminating customer and } \\
\text { market information; } \\
\text { - Evaluating marketing activities from } \\
\text { integrated process perspective; } \\
\text { - Fostering a demand rather than a } \\
\text { supply-based integration of } \\
\text { information needs. }\end{array}$ \\
\hline $\begin{array}{l}\text { Configuration - } \\
\text { Managing the structure } \\
\text { between the integrated } \\
\text { processes and customer } \\
\text { segments }\end{array}$ & $\begin{array}{l}\text { Linking external, customer-facing } \\
\text { segmentation with internal } \\
\text { segmentation of production, } \\
\text { logistics and sourcing; } \\
\text { - Obtaining knowledge about changes } \\
\text { in customer needs as a basis for } \\
\text { structural adaptation requirements } \\
\text { of the supply chain. }\end{array}$ \\
\hline $\begin{array}{l}\text { Social interactions - } \\
\text { Managing the working } \\
\text { relationship } \\
\text { between marketing and SCM }\end{array}$ & $\begin{array}{l}\text { - Exchanging information with SCM } \\
\text { such as defined customer segments } \\
\text { and new customer/product } \\
\text { opportunities; } \\
\text { - Collaboration within SCM partners } \\
\text { for information sharing. }\end{array}$ \\
\hline
\end{tabular}

Similar study highlights this by comparing how different firms are achieving competitive advantages by DCM or SCM and states those adopting the demand driven business models focuses more towards coordination and management of demand process. This is mainly achieved through the provision of higher customer value and the fulfilment of market demands. Whereas, firms focusing the supply driven business models focuses more towards coordination and management of the supply process (SCM) which allows to attain competitive advantage by providing comparative value at a lower cost [8]. Hence, it's easily reflected that marketing focuses towards creation of customer value and supply chain is focused towards supply related processes with the efficient use of resources. Thus demand chain is providing the linkage to bridge the gap between the marketing and supply chain principles. Research also facilitated a cross functional study to capture supply and demand integration. Based on the research results, researchers were able to introduce and propose a conceptual framework with three integrative elements and propositions for the role of marketing in DCM to enable the linkage and relationships between marketing and SCM, as highlighted in table 1 [7]. In this case, the demand chain transformation at Heineken Company is examined in some major aspects including ECR with the form of category management, vendor management inventory (VMI) and early supplier involvement (ESI) as useful practices [9]. Moreover, many successful companies like Zara and Dell benefit from adoption of the DCM principles to their businesses [10] in order to increase their profitability and competitive advantage by close association of supply and customer elements such as product availability, delivery accuracy and responsiveness. Authors also suggest that it is essential for the marketing department to consider other SC entities information into their decision making and limit their responsibilities to focus on integration of supply-demand processes. According to their findings, marketing will be resilient to alterations and hence, the whole supply chain needs to be involved in marketing activities, customer priority decisions and more significantly needs to deny marketing decisions if they are not in line with business profitability. In essence, they suggest that the relationship triangle of SCM, DCM and marketing can act as a business enhancement option which also creates the superior customer value $[7,10]$.

\section{B. New Product Development and Manufacturing}

It is evidenced that manufacturing firms in order to be more competitive in market, must continuously update their product offers in order to better satisfy the customers' requirements. The integrated NPD-SCM enterprise has the benefit of increased supply chain capability, thus increasing the effectiveness of new product introductions and improves enterprise's performance [11]. NPD relates to most departments in the manufacturing companies, while the main sections such as marketing, design and engineering sections should be included in. Marketing departments are the one to connect industry with customers and their role is to capture the knowledge of customer requirements, market analysis and opportunities to produce new product. The department which defines product concepts as to meet customer requirements is Design; they are the one who creates realistic requirements after the approval of customer. Manufacturing function is basically an engineering department which defines the requirements for material purchase, distribution, and the whole supply chain. Research studies demonstrate that NPD innovation is also important towards achieving success within manufacturing processes and is necessary to meet the requirements and expectations of the customers. Similarly, innovation within organisation is often depicted as useful change tool that can be incremental or radical within the product or process and a measure towards the success of the product and that of the organisation within the competitive market place. Within the current global environments, companies have to adopt and 
practice innovative principles and methods to their product and service functions to enable them to compete within the markets while reducing the product life cycle and lead times to meet the demands [12]. Researchers identify product innovation as a critical element to the success of the product which is highly related to the sustainable business success in turn providing better business opportunities for growth, expansion and maturity within new areas. Similarly, process innovation refers to the aspect of using new innovative production and operations methods and using new technological advancements such as additive manufacturing to improve their overall production processes. Similar study has emphasized heavily upon process innovation that could result in product innovation and likewise product innovation which could force process innovation on manufacturing organisations. This further proves that there is a strong linkage of product and process innovation that should be considered as an important factor during the NPD process [13]. Finally, market innovation is considered as a newer approach which companies have been adopting in order to scale and utilise the target market. This is also linked to the wider discussion of innovation and especially product innovation towards market research, advertising and promotion, which also relates heavily towards using the four Ps concepts for any new opportunities within the market, including entry and threats of new markets. The concept of market innovation is very central and important to product innovation and likewise product innovation is the central focus for product novelty [12].

\section{NPD and Demand Chain Management}

Research defines Product Development as the transformation process of a market opportunity and a set of assumptions regarding product technology into a product accessible for marketplace [14]. According to Figure 1, three critical elements for NPD effectiveness are required. First, it is essential to match the design capabilities of the supplier to the company's consumption. In other words, the buyer's firm should choose the right supplier in order to increase NPD team success. Secondly, firms should consider the supplier's technical metrics regarding their potentials for project application and quality. Therefore, gaining access to the new technological developments, purchaser firms should manage joint associations with their strategic suppliers effectively. Thirdly, firms should assess suppliers for business variables such as schedule, cost and agenda for final success in NPD. While suppliers have sufficient technical expertise, they could either discuss and share the technology or set the goals for project results. For instance, it was observed that in the case of a leading Japanese firm, prior to a new product design, they visit the key suppliers in order to evaluate them for producing an item with the specific targeted quality and cost levels [15]. They also investigate the supplier qualifications for becoming an element of a NPD team. Afterwards, supplier firm provide an initial design for products and then both companies' engineers corporate together in order to find substitute design processes to develop a product prototype for with the best specifications as possible.

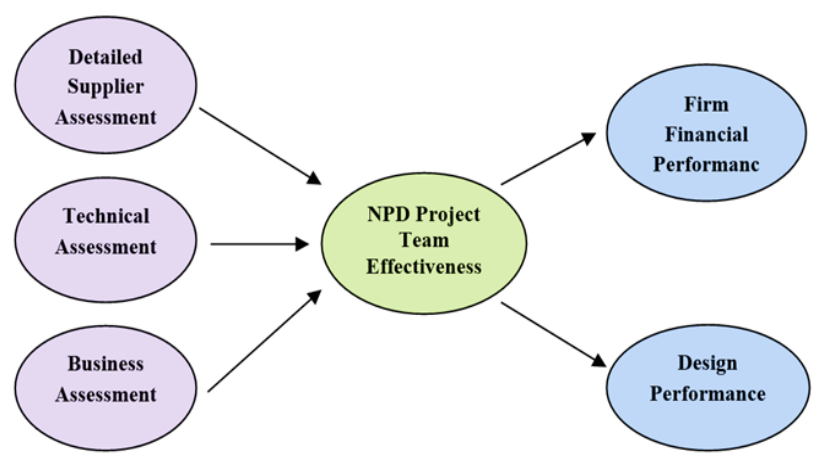

Fig. 1. Systematic process for supplier integration within new product development environments [15].

As a result of the NPD project, in the right side of the diagram, the project increasing sales, profits and return on investment for both supplier and buyer (time, staff, and fund) imply the firm financial performance. Besides, low-cost design for the supplier and low-cost finished product for the buyers imply the design performance of NPD.

\section{Sustainable Development and Green Product Development}

The authors have described sustainable production and consumption as 'involving business, government, communities and households contributing to environmental quality through the efficient production and use of natural resources, the minimization of wastes and the optimization of products and services' [16]. Sustainable development aims to an undefinable and unachievable goal which worth targeting for but does not ever reach to an actual arrival point. Along with the financial, legislations and staff pressure, market pressure plays an important role in changing the industrial behaviour towards sustainable practices and some companies set some guidelines called “suppliers' charter" introducing the environmental criteria they require from their supplier firms [17]. From the marketing perspective, one of the most frequent issues regarding the green products is the high costs involved and their premium price that often causes the product failure [18]. One of the major reasons for the eco-friendly products' higher price is the low market demand and the new concept of greening that lead the manufacturers to produce cheaper products regardless of their life cycle, maintenance costs and environmental impacts. Eco-friendly is getting famous gradually, however it is still an emerging industry that have not been placed in people routine life and purchasing selections, especially in the developing countries. Hence, this is a very critical aspect of green products' premium price as people are not still wellinformed and cultivated regarding the benefits of such products and hence the demand is low. Besides, some countries have officially coined the eco-labelling schemes as trustworthy symbols attached to the products in order to provide consumers with independent information regarding the products they purchase and help them change their consumption patterns towards getting more environmental responsible [19]. 


\section{E. New Product Devlopment and Sustainable Practices}

Sustainability related opportunities refers to solutions for existing sustainability problems and towards appropriate sustainable products and services or product-service combinations [20]. Managing sustainability oriented opportunities is thus based on the search for innovations relating to what could be improved and should be done [21]. With the change in customer demand and that of newer practices been adopted within the product based manufacturing environments, companies are now operating in lesser secure and more complex environments to facilitate the change in their manufacturing requirements. Due to the focus on low cost, highly responsive and flexible short product lifecycle needs, organisations and manufacturers are becoming more sustainable towards their approaches. Sustainability not only focuses on current production and operations strategies but to achieve growth, stability and maturity for future business operations. This however implies that organisation's focus is now towards short term high value manufacturing than just long term relationship development between all parties within the supply chain, including supplies and customer relationships focus.

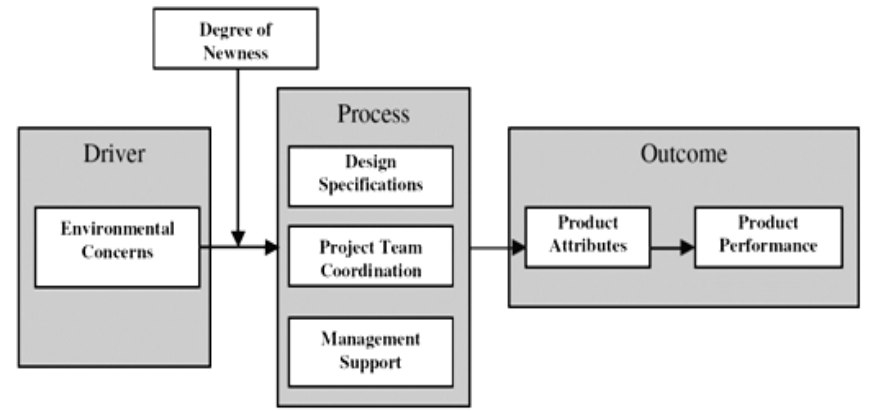

Fig. 2. Influence of environmental concerns on product performance [22].

To achieve this, manufacturers would need to enhance their operational abilities through adopting and linking the traditional manufacturing requirements such as lean and agility with wider business strategies including, marketing, sales, technology adoption and product and process innovation measures within their environments [23]. Hence, the concept of NPD and Sustainability is highly important aspect that focuses on organisations to introduce new markets that enables their growth through higher customer and product diversification measures. NPD development teams will be dealing with three important factors when aiming to incorporate environmental concerns and NPD. Different aspects of greening related to design specifications such as market demands, environmental attributes and product functionalities make greening a complex procedure. From market perspective, some aspects of product specifications that are important by a development team might not be important to consumers and they might have a neutral vision regarding the environmental aspects of the product they purchase. When focusing on these parameters, due to their misalignment with customer preferences, the chances of new product success will be reduced. Likewise, there might be an incompatibility between environmental attributes and traditional products attributes, or product functionalities like safety and reliability. Effective communication and cooperation between different entities and NPD teams would be a very beneficial factor for product success [24, 25]. However, various interpretations about innovation and different mind-sets of people in large firms seem to be a barrier and cause the failed performance of the new products.

\section{RESEARCH METHODOLOGY}

The structure and scope of this research will be based on incorporation of NPD and DCM that is considered by all the business ecosystem entities to facilitate the product portfolio novelty and to create unique competitive advantages through linkage of customer values by an effective flow of products. Moreover, environmental sustainability and business ethics are considered as significant bedrocks in generation of new products within any manufacturing sector.

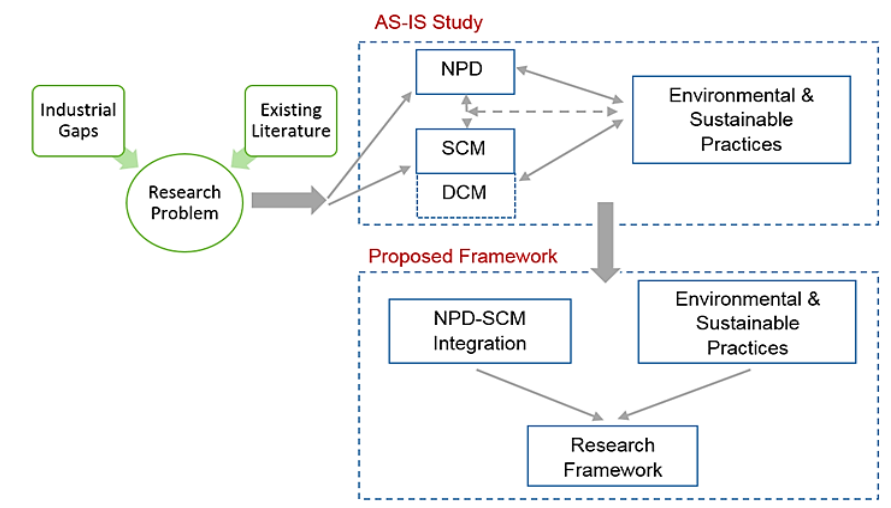

Fig. 3. Proposed research framework.

The critical analysis of the literature review creates a proper foundation for the adoption of further method based on case study investigation of manufacturing suppliers. Within the next stages of this research, a set of different approaches and methodologies are planned towards fulfilment of the key research objectives. Further methodology seeks to collect, synthesize and analyse data in a designed structure. The proposed research framework is designed to provide an accurate and effective roadmap towards the scope of the research. As evident from figure 3, existing research gaps within manufacturing industries and the literature would prepare the AS-IS as input data towards major research concepts. The research gaps of knowledge within the proposed area were identified by exploration of the current literature in initial research stages, highlighted within this paper.The research gaps and questions are illustrated further in figure 4 .

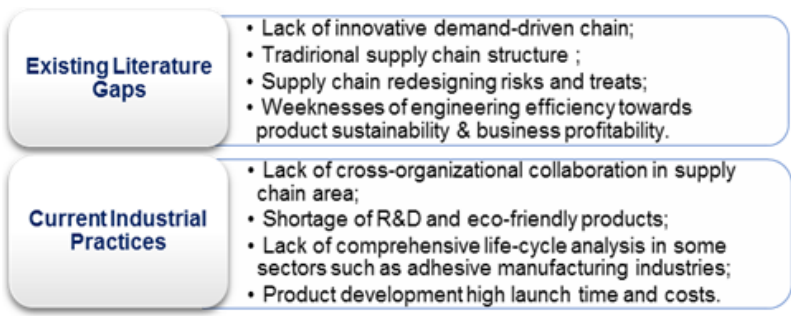

Fig. 4. Research gaps and research questions. 
They will be addressed through the evidence-based research established on a mixed method data. Consequently, the effective linkage between the research elements will create the research framework for the critical discussions and recommendations for further research.

\section{CONCLUSIONS AND FUTURE RESEARCH}

The research gaps existing in this field that need to be addressed would be lack of innovative demand-driven chain, lack of cross-organizational collaboration and shortage of R\&D for eco-friendly products in developing countries. Hence, the research has identified the linkage of the demand chain and that of the importance of sustainable practices adopted within the new product development aspects of operations within manufacturing companies. The paper also demonstrates that manufacturing firms need to access and observe closely the role and impact of marketing activities within the demand chain management and sustainable strategies within the company. The close linkage between marketing and supply chain as two separate and non-related entities makes the DCM concept as the key value creation aspect for customer driven markets. Also, environmental sustainability and business ethics should be considered of significant importance towards the design and development of new products within the manufacturing sectors. Hence, our research study and that of findings also concludes the need to have further integration models linking environmental innovation and NPD by combining the customer expectations and demands in every aspect of product and process environments within the company. Finally, it was evident through our investigations and research that in order to be highly competitive and meeting the demands of the market, manufacturing companies must update the product variety and offerings continuously in order to satisfy the requirements of their customers. Operations and management within the company should use the supply chain features more frequently, as the increased rate of product introductions demands more from a business and needs more efforts to deliver the new products effectively and efficiently. Further investigation of the literature will be undertaken to identify more research gaps within the proposed field in order to support the detailed research objectives. The researchers also intend to present a novel framework of NPD-DCM to improve the engineering and manufacturing efficiency towards product sustainability as well as fulfilling the customer expectations within the market.

\section{REFERENCES}

[1] Y.H. Lun, K. Lai, C. Wong, and T.C.E Cheng, "Demand Chain Management in the container shipping service industry,” International Journal of Production Economics, vol 141, pp. 485-492, 2013.

[2] A. Awwad, and M.N. Akroush, "New product development performance success measures: an exploratory research," EuroMed Journal of Business, vol 11, pp. 2-29, 2016.

[3] C.A. Vural, "Sustainable demand chain management: An alternative perspective for sustainability in the supply chain,” Procedia-Social and Behavioral Sciences, vol. 207, pp. 262-273, 2015.

[4] D. Walters, "Demand chain effectiveness - supply chain efficiencies: a role of enterprise information management," Journal of Enterprise Information Management, vol 19, pp. 246-261, 2006.

[5] A. Caputo, G. Marzi, and M.M Pellggrini, "The internet of things in manufacturing innovation processes: development and application of a conceptual framework,” Business Process Management Journal, vol 22, pp. 383-402, 2016.

[6] S. Mahmood, and P.Kess, "An Overview of Demand Management through Demand Supply Chain in Fashion Industry," Journal of Management Sciene \& Business Administration, vol 2, pp. 7-19, 2016.

[7] U. Jüttner, M. Christopher, and S. Baker, "Demand chain managementintegrating marketing and supply chain management," Industrial Marketing Management, vol. 36, pp. 377-392, 2007.

[8] P. Hiletofth, "Demand supply chain management: industrial survival recipe for new decade,” Industrial Management \& Data Systems, vol. 111, pp. 184-211, 2011.

[9] T.E. Vollmann, and C. Cordon, "Building Successful Customer Supplier Alliances,” Long Range Planning, vol. 31, pp. 684-694, 1998.

[10] B. Walker, D. Bovet, and J. Martha, "Unlocking the supply chain to build competitive advantage," The International Journal of Logistics Management, vol. 11, pp. 1-8, 2000.

[11] R. Van Hoek, and P. Chapman, "How to move supply chain beyond cleaning up after new product development,” International Journal of Supply Chain Management, vol. 12, page 239-244, 2007.

[12] K. Vinayak, and R. Kodali, “The relationship between NPD innovation and performance: the moderating role of NPD best practices in Indian manufacturing industry,” Measuring Business Excellence, vol. 18, pp. 39-59, 2014.

[13] E. Maravelakis, N. Bilalis, A. Antoniadis, K.A. Jones, and V. Moustakis, "Measuring and benchmarking the innovativeness of SMEs: a threedimensional fuzzy logic approach,” Production Planning and Control, vol. 17, pp. 283-292, 2006.

[14] V. Krishnan, and K.T. Ulrich, "Product development decisions: A review of the literature,” Management science, vol. 47, pp. 1-21, 2001.

[15] K. Petersen, R. Handfield, and G.Ragatz,"Supplier integration into new product development: coordinating product, process and supply chain design,” Journal of Operations Management, vol. 23, pp. 371-88. 2005.

[16] Brundtland Commission, WCED. Our Common Future. Oxford: Oxford University Press, 1987.

[17] D. Mackenzie, L. Moss, J. Engelhardt, and R. Martyn, Green design: design for the environment. London: Laurence king, 1991.

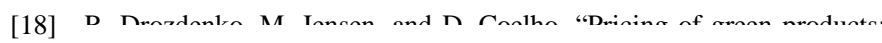
Dramiume naid soncumar sharastarictire and insontivac" Intarnational Journal of Business, Marketing, and Decision Sciences, vol. 4, pp.106116, 2011.

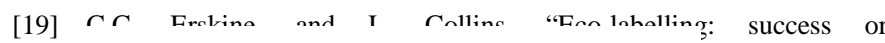
failure?,” Environmentalist, vol. 17, pp.125-133, 1997.

[20] E.G. Hansen, F. Große-Dunker, and R. Reichwald, "Sustainability innovation cube: framework to evaluate sustainability-oriented innovations,” International Journal of Innovation Management, vol. 13, pp. 683-713, 2009.

[21] S. Schaltegger, and R. Burritt, "Measuring and managing sustainability performance of supply chains Review and sustainability supply chain management framework," Supply Chain Management: An International Journal, vol. 19, pp. 232- 241, 2014.

[22] L, Berchicci, and W. Bodewes, "Bridging environmental issues with new product development,” Business Strategy and the Environment, vol. 14, pp. 272-285, 2005.

[23] D.T. Pham, and A.J. Thomas, "Fit manufacturing: a framework for sustainability,” Journal of Manufacturing Technology Management, vol. 23, pp. 103-123, 2011.

[24] R.G. Cooper, and E.J. Kleinschmidt, "Benchmarking the firm's critical success factors in new product development," Journal of Product Innovation Management, vol. 12, pp. 374-391, 1995.

[25] D. Dougherty, "Interpretive barriers to successful product innovation in large firms,” Organization Science, vol. 3, pp. 179-202, 1992. 